\title{
Clozapine as a Model for Antipsychotic Development
}

\author{
Frederick C. Nucifora $\mathrm{Jr}^{1} \cdot$ Marina Mihaljevic $^{2} \cdot$ Brian J. Lee $^{1} \cdot$ Akira Sawa $^{1}$
}

Published online: 26 June 2017

(C) The American Society for Experimental NeuroTherapeutics, Inc. 2017

\begin{abstract}
Schizophrenia is a devastating illness that affects up to $1 \%$ of the population; it is characterized by a combination of positive symptoms, negative symptoms, and cognitive impairment. Currently, treatment consists of one class of medications known as antipsychotics, which include typical (firstgeneration) and atypical (second-generation) agents. Unfortunately, antipsychotic medications have limited efficacy, with up to a third of patients lacking a full response. Clozapine, the first atypical antipsychotic developed, is the only medication shown to be superior to all other antipsychotics. However, owing to several life-threatening side effects and required enrollment in a registry with routine blood monitoring, clozapine is greatly underutilized in the US. Developing a medication as efficacious as clozapine with limited side effects would likely become the first-line therapy for schizophrenia and related disorders. In this review, we discuss the history of clozapine, landmark studies, and its clinical advantages and disadvantages. We further discuss the hypotheses for clozapine's superior efficacy based on neuroreceptor binding, and the limitations of a receptor-based approach to antipsychotic development. We highlight some of the advances from pharmacogenetic studies on clozapine and then focus on studies of clozapine using unbiased approaches such as pharmacogenomics and gene expression profiling. Finally, we examine how these approaches could provide insights into
\end{abstract}

Frederick C. Nucifora, Jr

nucifora@jhmi.edu

1 Department of Psychiatry and Behavioral Sciences, Johns Hopkins University School of Medicine, Baltimore, MD, USA

2 Clinic for Psychiatry, Clinical Center of Serbia, Belgrade, Serbia clozapine's mechanism of action and side-effect profile, and lead to novel and improved therapeutics.

Key Words Clozapine $\cdot$ Schizophrenia $\cdot$ Antipsychotic . Treatment refractory $\cdot$ Pharmacogenomics $\cdot$ Gene expression profiling

\section{Introduction}

Schizophrenia is a devastating illness that affects up to $1 \%$ of the population $[1,2]$, characterized by a combination of positive symptoms, negative symptoms, and cognitive impairment. Positive symptoms are abnormal mental experiences that include hallucinations, delusions, and thought disorder [3]. Negative symptoms relate to loss of mental energy and efficiency, such as limited emotional expression, apathy, social withdrawal, and poverty of thought and speech [3]. The cognitive decline associated with schizophrenia does not lead to gross dementia; it mainly affects executive functioning, verbal memory, and attention [3, 4]. The symptoms of schizophrenia can be tormenting to patients, greatly affecting their quality of life. In addition, lifetime suicide risk is $5 \%[5,6]$, mortality rate is 2 to 3 times higher than that of the general population [7], and life expectancy is $20 \%$ shorter [8].

Schizophrenia cost the US $\$ 155.7$ billion in 2013 , including $\$ 9$ billion in medication expenses [9]. Currently, treatment consists of one class of medications, known as antipsychotics that include typical (first-generation) and atypical (secondgeneration) agents. Despite their cost, antipsychotic medications have limited efficacy, with up to a third of patients lacking a full response $[10,11]$. Clozapine is the only medication indicated for treatment refractory schizophrenia, usually defined as the failure of 2 other antipsychotics for any reason. Up to $70 \%$ of refractory patients demonstrate improvement in 
their symptoms on clozapine, but the remaining $30 \%$ of patients tend to be refractory to all medications [12]. As we will describe in this review, the field desperately needs medications with improved efficacy and limited side effects.

\section{Development of First-Generation or Typical Antipsychotics}

The first antipsychotic identified was chlorpromazine, originally synthesized as an anesthetic adjunct. The French surgeon Henri-Marie Laborit noticed its unusual calming properties [13, 14], and later psychiatrist Heinz Lehmann performed clinical trials with chlorpromazine that led to US Food and Drug Administration (FDA) approval in 1954 [15]. The development of other typical antipsychotics in the late 1950s to mid-1970s were based on chemical structure and an agent's ability to cause catalepsy in rats $[15,16]$. Unfortunately, in many cases, these typical antipsychotics caused severe and debilitating movement disorders, including dystonia and tardive dyskinesia. This created a need for effective antipsychotics that do not cause movement disorders.

\section{Development of Clozapine and its Superior Efficacy}

Clozapine, the first atypical antipsychotic developed [15], has been termed atypical because, in contrast to typical antipsychotics, it does not produce significant extrapyramidal side effects, does not elevate prolactin levels, and does not induce tardive dyskinesia after long-term use [17, 18]. In preclinical studies clozapine appeared to be effective without causing catalepsy, which was surprising since at the time catalepsy was considered necessary for efficacy [13]. Unfortunately, as testing on clozapine was just beginning in the US, 16 patients in Finland developed agranulocytosis leading to 8 deaths, and clozapine was removed from the market in countries where it had been introduced $[13,15]$.

As the use of typical antipsychotics continued to increase, the number of patients that developed severe movement disorders also rose. This unfortunate situation renewed interest in clozapine, owing to its ability to treat schizophrenia with minimal risk of causing movement disorders, and led the FDA to consider approving clozapine only if it had superior efficacy to standard antipsychotic medications [15]. Therefore, in 1988, Kane et al. [19] conducted a multicenter clinical trial with 286 patients who failed to respond to haloperidol after 6 weeks, who were then randomly assigned to either clozapine or chlorpromazine for 6 weeks. This landmark study showed that $30 \%$ of the haloperidol nonresponders improved on clozapine in the Brief Psychiatric Rating Scale and the Clinical Global Impression Scale versus 4\% on chlorpromazine. Clozapine also resulted in a greater improvement in negative symptoms. This study was important because it showed that clozapine was superior to another antipsychotic, and that clozapine could successfully treat refractory schizophrenia. Following this study, clozapine received approval for refractory schizophrenia in the US. However, the FDA required that all patients on clozapine enroll in a registry with routine blood monitoring for agranulocytosis.

Two pivotal prospective studies substantiated clozapine's superiority among atypical antipsychotics. The first trial, the Clinical Antipsychotic Trials for Interventions Effectiveness (CATIE) phase II investigation, studied patients from the CATIE phase I trial that did not respond to 1 of the 4 atypical antipsychotics used originally (risperidone, quetiapine, ziprasidone, and olanzapine) [20]. Patients were then randomized to either clozapine or 1 of 3 atypical antipsychotics that they were not previously on (olanzapine, quetiapine, or risperidone). The main outcome was discontinuation of medication for any reason, as this best represents real-world prescribing practices. The study showed superior results for time to discontinuation with clozapine (median time of 10.5 months) versus quetiapine (median time of 3.3 months), risperidone (median time of 2.8 months), and olanzapine (median time of 2.7 months). Furthermore, the study demonstrated less discontinuation on clozapine, with $44 \%$ of the patients completing the 18-month study versus $18 \%$ for the other medications. In addition, at 3 months, the patients on clozapine showed significant improvement in their Positive and Negative Syndrome Scale (PANSS) total scores compared with patients treated with quetiapine or risperidone (but not olanzapine).

The second study, performed in the UK, and termed the Cost Utility of the Latest Antipsychotic Drugs in Schizophrenia Study (CUtLASS 2) [21], attempted to determine if clozapine was more efficacious than other antipsychotics in its class. Patients with schizophrenia or related disorders who had failed at least 2 other antipsychotics owing to poor response were randomized to clozapine or either risperidone, olanzapine, quetiapine, or amisulpride. At 1 year follow-up, patients on clozapine had a significant improvement in PANSS total score and a trend towards improvement in quality-of-life score compared with the other antipsychotics. In addition, at 3 months, patients on clozapine reported greater improvement in their overall mental health than patients on other antipsychotics in its class.

Meta-analyses of antipsychotic medications have consistently demonstrated that clozapine is superior to all other antipsychotics [22]. However, standard meta-analysis cannot provide a hierarchy of antipsychotic efficacy. Therefore, Leucht et al. utilized a Bayesian-framework, multipletreatments meta-analysis of randomized controlled trials to compare antipsychotics and placebo in the acute treatment of schizophrenia [23]. They identified 212 studies that met their inclusion criteria with a total of 43,049 participants, and determined that clozapine was significantly more effective than the 14 other antipsychotics included (amisulpride, olanzapine, 


\begin{tabular}{lll}
$\begin{array}{l}\text { Antipsychotic } \\
\left({ }^{*} \text { typical) }\right.\end{array}$ & Overall change in symp \\
\hline Clozapine & -0.88 & $(-1.03$ to -0.73$)$ \\
Amisulpride & -0.66 & $(-0.78$ to -0.53$)$ \\
Olanzapine & -0.59 & $(-0.65$ to -0.53$)$ \\
Risperidone & -0.56 & $(-0.63$ to -0.50$)$ \\
Paliperidone & -0.50 & $(-0.60$ to -0.39$)$ \\
Zotepine & -0.49 & $(-0.66$ to -0.31$)$ \\
Haloperidol ${ }^{*}$ & -0.45 & $(-0.51$ to -0.39$)$ \\
Quetiapine & -0.44 & $(-0.52$ to -0.35$)$ \\
Aripiprazole & -0.43 & $(-0.52$ to -0.34$)$ \\
Sertindole & -0.39 & $(-0.52$ to -0.26$)$ \\
Ziprasidone & -0.39 & $(-0.49$ to -0.30$)$ \\
Chlorpromazine ${ }^{*}$ & -0.38 & $(-0.54$ to -0.23$)$ \\
Asenapine & -0.38 & $(-0.51$ to -0.25$)$ \\
Lurasidone & -0.33 & $(-0.45$ to -0.21$)$ \\
lloperidone & -0.33 & $(-0.43$ to -0.22$)$
\end{tabular}

Standardized mean difference ( $95 \%$ credible interval)

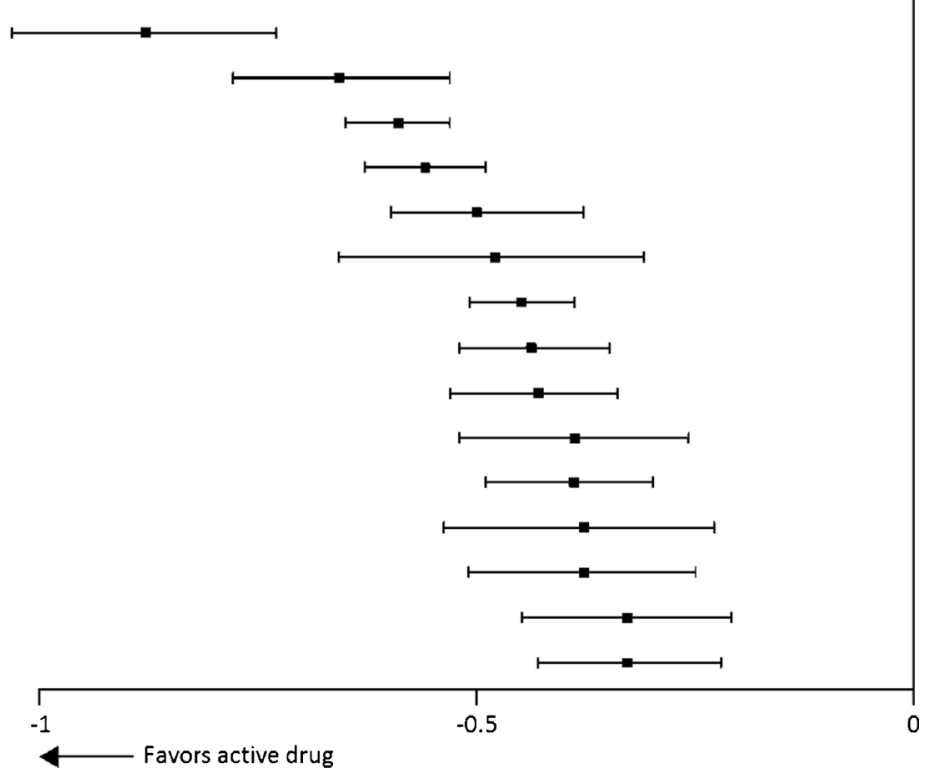

Fig. 1 Efficacy of antipsychotic medications. Adapted from Leucht et al. [23]

risperidone, paliperidone, zotepine, haloperidol, quetiapine, aripiprazole, sertindole, ziprasidone, chlorpromazine, asenapine, lurasidone, and iloperidone). In fact, it was the only medication available in the US to separate from all other antipsychotics in efficacy (Fig. 1).

Furthermore, clozapine is the only medication to have an FDA indication for reducing the risk of recurrent suicidal behavior in patients with schizophrenia or schizoaffective disorder [24]. Clozapine received this indication after an international multicenter randomized study, conducted over 2 years, demonstrated a $25 \%$ improvement over olanzapine for all measures of suicidality (reduction in suicide attempts, hospitalization, and a scale for quantifying suicidality). In addition, clozapine has been shown to reduce violence [25].

\section{Disadvantages of Clozapine}

\section{Clozapine's Side-Effect Profile}

Despite clozapine's superior efficacy, it has several lifethreatening side effects. Agranulocytosis (now called severe neutropenia) occurs when the absolute neutrophil count is $<$ $500 / \mu \mathrm{l}$. The risks are estimated to be $0.8 \%$ for severe neutropenia and 3\% for neutropenia [26]. As agranulocytosis or severe neutropenia can lead to death, the FDA instituted the clozapine Risk Evaluation and Mitigation Strategies (REMS) registry. All patients on clozapine must enter this registry with weekly blood monitoring of their absolute neutrophil count for the first 6 months, every 2 weeks for the next 6 months, and then monthly for as long as the patient is on clozapine.
The establishment of a national registry has dramatically reduced the expected deaths from clozapine [27].

Myocarditis occurs in 1 out of 10,000 to 1 out of 500, with a mortality rate of up to $50 \%$ [28]. Approximately $80 \%$ of the incidents of myocarditis occur within the first month and $90 \%$ by 2 months. Clozapine can also cause venous thromboembolism, with an estimated mortality rate of $44 \%$ [29]. Close following of electrocardiograms, troponins, and C-reactive protein during the first 2 months can mitigate cardiovascular events.

The risk of developing seizures can be up to $10 \%$ after 3.8 years [30, 31]. However, seizures arising from clozapine treatment are not a contraindication and clozapine can be continued with the co-administration of an antiseizure medication. Gastrointestinal hypomotility occurs in approximately $14 \%$ of patients with a mortality rate as high as $27.5 \%$ [32]. A mean weight gain of $30 \mathrm{lb}$ was observed in a 10-year cohort, with most weight gain occurring during the first 6 to 12 months. Finally, clozapine is also associated with a high risk of developing diabetes mellitus [33]. Unfortunately, gastrointestinal hypomotility and metabolic disturbances remain problematic despite monitoring.

\section{Clozapine is Underutilized}

Clozapine has been underutilized in the US, owing to its lifethreatening side effects, the difficulty in initiating the medication safely, the need for regular blood monitoring, and the often disorganized nature of patients requiring clozapine [10, 22]. Furthermore, this has led to the use of high doses of other antipsychotics, polypharmacy with multiple antipsychotics, or 
high doses of multiple antipsychotics, which greatly increase the likelihood of adverse events and still only lead to limited improvement in clinical symptoms [10]. Collectively, up to $40 \%$ of all patients with schizophrenia and related disorders could benefit from clozapine [10, 34]. However, in the US only $4.4 \%$ of patients were on clozapine in 2008 [34], with an average delay of about 48 months in starting clozapine [35], which could worsen long-term prognosis [36]. Taken together, there is a critical need to develop a medication at least as effective as clozapine but with fewer side effects. In fact, a medication achieving this aim would likely be the firstline antipsychotic therapy.

\section{Clozapine as a Model for Drug Development: Neuroreceptors}

\section{Hypotheses on the Superior Efficacy of Clozapine}

In order to develop a medication as effective as clozapine with fewer side effects, we need to understand clozapine's mechanism of action. Importantly, to date, no antipsychotic medication approved for the treatment of schizophrenia has been efficacious unless it binds to the dopamine $\mathrm{D}_{2}$ receptor [37]. However, the strength and pattern of binding with other neuroreceptors influences the efficacy and side-effect profile (Table 1).

Several hypotheses exist for clozapine's superior efficacy (Table 2). Studies on antipsychotic pharmacology originally suggested that $\mathrm{D}_{2}$ receptor occupancy of at least $70 \%$ was necessary for efficacy [45]. Interestingly, clozapine has < $70 \%$ occupancy at the $\mathrm{D}_{2}$ receptor $[46,47]$, leading to the hypothesis that low $\mathrm{D}_{2}$ receptor occupancy may underlie the superiority of clozapine [48]. However, quetiapine also has a low $\mathrm{D}_{2}$ receptor occupancy but lacks clozapine's efficacy.

A second hypothesis relates to the rapidity of dissociation from the $\mathrm{D}_{2}$ receptor [49]. Antipsychotics have different dissociation constants, or rates at which they dissociate from receptors. Clozapine has a high dissociation constant for $\mathrm{D}_{2}$, which is even higher than that of dopamine itself [50]. However, this alone cannot explain clozapine's superior efficacy, as quetiapine also has a comparable dissociation constant.

A third hypothesis suggests that a higher ratio of affinity for the serotonin 5-hydroxytryptamine $(5-\mathrm{HT})_{2 \mathrm{~A}}$ receptor compared with the dopamine $\mathrm{D}_{2}$ receptor mediates clozapine's superior efficacy [48, 51]. However, most atypical antipsychotics share a high ratio of $5-\mathrm{HT}_{2 \mathrm{~A}} / \mathrm{D}_{2}$ receptor affinity. Moreover, amisulpride, the second most efficacious medication in the ranking meta-analysis by Leucht et al. [23], has little-to-no serotonin receptor affinity. In addition, $5-\mathrm{HT}_{2 \mathrm{~A}}$ receptor antagonists have not been successful in treating psychosis [52].
A fourth hypothesis is centered on the finding that clozapine has high dopamine $\mathrm{D}_{4}$ receptor affinity and has a higher ratio of affinity for the $\mathrm{D}_{4}$ receptor than the $\mathrm{D}_{2}$ receptor [53]. However, olanzapine and ziprasidone also have high affinity for the $\mathrm{D}_{4}$ receptor, and asenapine has a similar ratio of $\mathrm{D}_{4} / \mathrm{D}_{2}$ affinity. Also, $\mathrm{D}_{4}$ antagonists have not shown efficacy in clinical trials [54].

\section{Binding at Other Receptors}

In addition to dopamine and serotonin receptors, clozapine binds $\alpha$-adrenergic, muscarinic, and histamine receptors (Table 1). Some evidence suggests that $\alpha 1$ receptors may affect positive symptoms, while $\alpha 2$ receptors may affect negative and cognitive symptoms [55]. However, the $\alpha 1$ antagonist prazosin [56] and $\alpha 2$ agonist guanfacine did not show clear clinical benefit in improving symptoms of schizophrenia [57].

Clozapine and its metabolite $\mathrm{N}$-desmethylclozapine (NDMC) are potent M1 agonists. Rajji et al. [58] found that the ratio of clozapine to NDMC is negatively correlated with working memory performance. Muscarinic agonists have been investigated for their beneficial effects on cognition and psychosis, and the M1/M4 preferring agonist xanomeline led to improvement in cognitive performance, total PANSS scores, and total Brief Psychiatric Rating Scale scores, but also caused significant gastrointestinal intolerance $[59,60]$. It is unclear whether affinity of the M1 receptor contributes significantly to clozapine's unique mechanism of action, as olanzapine shares its high muscarinic affinity without its superior efficacy.

Both clozapine and NDMC are inverse agonists of the H1 and $\mathrm{H} 2$ histamine receptors [61]. $\mathrm{H} 2$ antagonism showed some clinical benefit in a randomized clinical trial of patients with treatment-resistant schizophrenia [62]. However, olanzapine also has high histamine receptor affinities [63], but without superior efficacy.

It is possible that clozapine's superior efficacy is mediated by its affinity for a broad array of neuroreceptors. The combination of these receptor affinities may enhance its efficacy, each with additive but variable contributions. However, many of clozapine's side effects also result from binding to these receptors. Finally, it should be noted that olanzapine has a similar structure to clozapine but is not as efficacious.

\section{Pimavanserin}

Pimavanserin is an example of a recently developed medication based on neuroreceptor binding. In the treatment of Parkinson's disease psychosis (PDP), clozapine and quetiapine are typically used at low doses that only partially block the $\mathrm{D}_{2}$ receptor. However, at these doses, they still have significant serotonin $5-\mathrm{HT}_{2} \mathrm{~A}$ receptor blockade, and can 


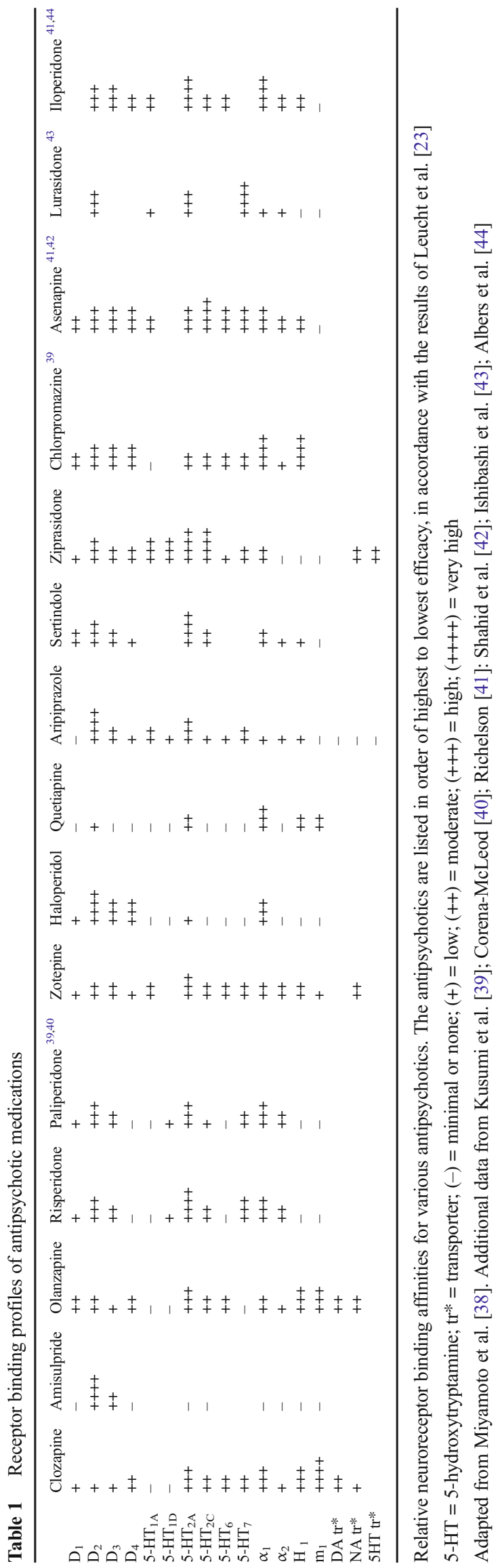

ameliorate psychosis. This observation led to the hypothesis that a serotonin receptor inverse agonist, which binds to the serotonin receptor and decreases its intrinsic activity, may be useful in treating psychosis. Pimavanserin is a novel serotonin receptor inverse agonist that lacks activity at dopamine, muscarinic, adrenergic, and histamine receptors [64], and has recently been approved for PDP, as it reduced hallucinations and delusions in patients with PDP [65].

While pimavanserin is currently only approved for PDP, evidence suggests that it is effective as an adjunct to other antipsychotics for the treatment of schizophrenia. In a multicenter, randomized double-blind trial with 423 patients, Meltzer et al. [66] determined that the addition of pimavanserin to a dose of risperidone unlikely to treat psychosis [risperidone $2 \mathrm{mg}+$ pimavanserin (RIS2PIM)] was as effective as a dose of risperidone known to be effective for psychosis [risperidone $6 \mathrm{mg}+$ placebo (RIS6PBO)] at the end of 6 weeks. Interestingly, the RIS2PIM group showed a larger proportion of patients with $\geq 20 \%$ improvement in the PANSS at day 15 than the RIS6PBO group. Furthermore, the RIS2PIM group had less weight gain and less increase in their prolactin levels than in the RIS6PBO group. These results suggest that pimavanserin is a promising addition to antipsychotic management and strengthen the hypothesis that serotonin receptors contribute to the efficacy of antipsychotics. Although currently no study compares pimavanserin with clozapine, it is unlikely that pimavanserin will show superior efficacy. However, augmenting clozapine with pimavanserin may allow for lower dosing of clozapine and potentially fewer side effects.

There are now over a dozen antipsychotics on the market, with more in the pipeline since the development of clozapine, but none has matched or improved on clozapine's efficacy. Given this poor track record, it seems unlikely that additional efforts focused on altering neuroreceptor binding profiles will achieve success. This highlights the need to develop new approaches to antipsychotic development based on clozapine.

\section{Clozapine as a Model for Drug Development: Frontline Approaches}

The superior efficacy of clozapine can be investigated in 2 ways to advance the treatment of schizophrenia. One is to understand the genetics of patients that show response or side effects on clozapine. This approach would maximize the successful use of clozapine, providing an important framework for the implementation of personalized medicine in psychiatric care. The second is to understand the molecular mechanisms of clozapine, from receptor binding through downstream genes and pathways. This approach could identify new and specific targets for medications that provide improved efficacy and reduced side effects. To better understand 
Table 2 Hypotheses for clozapine's superior therapeutic efficacy based on neuroreceptor binding profiles

\begin{tabular}{|c|c|c|}
\hline Hypothesis & $\begin{array}{l}\text { Evidence for hypothesis } \\
\text { (aspects of clozapine) }\end{array}$ & $\begin{array}{l}\text { Evidence against hypothesis } \\
\text { (aspects of less efficacious antipsychotics) }\end{array}$ \\
\hline \multirow{2}{*}{$\begin{array}{l}\text { Dopamine } \mathrm{D}_{2} \\
\text { receptor }\end{array}$} & Low $\mathrm{D}_{2}$ receptor occupancy & Quetiapine: low $\mathrm{D}_{2}$ receptor occupancy \\
\hline & $\begin{array}{l}\text { Rapid } \mathrm{D}_{2} \text { receptor } \\
\quad \text { dissociation }\end{array}$ & Quetiapine: rapid $\mathrm{D}_{2}$ receptor dissociation \\
\hline \multirow{4}{*}{$\begin{array}{l}\text { Dopamine } \mathrm{D}_{4} \\
\text { receptor }\end{array}$} & \multirow[t]{2}{*}{ High $\mathrm{D}_{4}$ receptor affinity } & Olanzapine: high $\mathrm{D}_{4}$ receptor affinity \\
\hline & & Ziprasidone: high $\mathrm{D}_{4}$ receptor affinity \\
\hline & \multirow{2}{*}{$\begin{array}{l}\text { High } \mathrm{D}_{4} / \mathrm{D}_{2} \text { receptor affinity } \\
\quad \text { ratio }\end{array}$} & Asenapine: high $\mathrm{D}_{4} / \mathrm{D}_{2}$ receptor affinity ratio \\
\hline & & $\mathrm{D}_{4}$ receptor antagonists ineffective \\
\hline \multirow[t]{3}{*}{$\begin{array}{l}\text { Serotonin } \\
\text { receptors }\end{array}$} & \multirow[t]{3}{*}{$\begin{array}{l}\text { High } 5-\mathrm{HT}_{2 \mathrm{~A}} / \mathrm{D}_{2} \text { receptor } \\
\text { affinity ratio }\end{array}$} & $\begin{array}{l}\text { Most atypical antipsychotics: high } 5-\mathrm{HT}_{2 \mathrm{~A}} / \mathrm{D}_{2} \text { receptor } \\
\text { affinity ratio }\end{array}$ \\
\hline & & $\begin{array}{l}\text { Amisulpride: low } 5-\mathrm{HT}_{2 \mathrm{~A}} \text { receptor affinity (but highest } \\
\text { efficacy after clozapine) }\end{array}$ \\
\hline & & $5-\mathrm{HT}_{2 \mathrm{~A}}$ receptor antagonists ineffective \\
\hline
\end{tabular}

5-HT = 5-hydroxytryptamine the response, side effects, and mechanism of action of clozapine, the following approaches have been utilized: 1) the pharmacogenetic approach-hypothesis-driven candidate gene association studies; 2) the pharmacogenomic approach - hypothesis-free genome-wide association studies (GWAS); and 3) gene expression profiling — unbiased studies such as microarray and RNA-seq.

\section{Pharmacogenetics}

Pharmacogenetic approaches related to clozapine have focused on identifying genetic variants that could predict therapeutic response or the likelihood of developing side effects. To date, pharmacogenetic research has emphasized the major neurotransmitter systems involved in the pharmacodynamics and pharmacokinetics of antipsychotics. While issues with consistency exist in the findings [67-70], many of these associations could still be important. Several reasons may underlie the inconsistent results, such as different duration of clozapine treatment among the studies, different inclusion criteria for clozapine responders [23], and different ethnicities [71-74].

There are a number of reviews in the literature that discuss pharmacogenetics in more detail [70, 75-77]. Here we highlight some of the most recent systematic reviews and metaanalyses [67-69]. Potentially the most significant results regarding pharmacogenetics come from the serotonergic system and its genetic variants (rs6313 and rs6314) in the HTR2A gene, which encodes the $5-\mathrm{HT}_{2 \mathrm{~A}}$ receptor. Interestingly, the first meta-analysis published in 1998 [75] and the most recent meta-analysis from 2016 [67] supported results that the GG genotype of rs6313 and T allele carriers of rs6314 have poorer response on clozapine. However, some studies found negative associations [71, 72, 78-81].
Regarding clozapine pharmacokinetics, a recent systematic review revealed that genetic variants of the CYP450 system did not show reproducible results but identified novel findings for the $A B C B 1$ gene, which encodes a P-glycoprotein drug transporter [69]. Krivoy et al. [69] highlighted that the $A B C B 1$ gene was the only gene involved in pharmacokinetics found to be significant for both clozapine response and clozapine plasma concentrations. However, negative associations in the Japanese [73] and Chinese Han populations [74] were also recently reported.

Pharmacogenetic studies have elucidated some of the genetics of response and side effects to clozapine. However, these studies have focused mainly on the neurotransmitter systems thought to be relevant to clozapine's therapeutic response, and identification of novel targets is limited by a candidate approach. As antipsychotics that were developed based on finetuning the neurotransmitter receptor binding profile have not improved on the efficacy of clozapine, further candidate studies on neurotransmitter systems are unlikely to yield new insight on clozapine's mechanism of action or side effects. Therefore, new approaches are needed to match or improve on clozapine's efficacy while reducing its side effects. In the next subsection, we describe how unbiased approaches can lead to a better understanding of drug design and new therapeutic targets.

\section{Pharmacogenomics}

Unbiased information about the mechanisms of clozapine's efficacy and side effects can be obtained through pharmacogenomics and gene expression profiling. These studies have the potential to identify biological properties of clozapine and etiological factors of schizophrenia. They also provide novel targets from neuroreceptors to downstream genes and pathways, which are not limited by a candidate 
approach. Insight gained from the pharmacogenomics approach could therefore help inform drug development. We now highlight unbiased genomic studies utilizing human patients treated with clozapine or human brain tissue from patients treated with clozapine.

\section{Response}

Schizophrenia is likely caused by a combination of genetic and environmental influences [82-84]. From a genetic standpoint, schizophrenia is most often caused by many common genetic variants, each with a small effect size [85]. One way to assess the genetic burden of an individual is to use polygenic risk scores (PRS), or the aggregated genetic load of traitassociated alleles across many loci [86, 87]. From a clinical perspective, the greater the PRS, the higher the disease risk. PRS are obtained by selecting single-nucleotide polymorphisms (SNPs) associated with a phenotype of interest from GWAS samples and creating a sum of their phenotype associated alleles [86, 88]. This is important because many SNPs may not meet genome-wide significance alone, but together they may be significant. PRS have been used for a number of studies addressing the genetic bases of mental illness [85, 88].

Recently, Frank et al. [89] revealed increased PRS, using data from a GWAS of schizophrenia, in patients with a history of clozapine treatment versus clozapine-naive patients. In addition, they found increased PRS in clozapine responders versus nonresponders. These data provide potential insights into the biology of refractory schizophrenia, suggesting that patients who require clozapine have a higher genetic risk burden. These results are relevant for drug development as higher PRS may indicate that multiple target genes and pathways are involved in severe cases of schizophrenia, and could require a combination of medications for treatment. This further necessitates understanding the downstream targets of clozapine to design more effective medications.

Furthermore, Ruderfer et al. [90] demonstrated that increased genetic risk variants track with clozapine treatment. They used the significant genomic regions identified from the GWAS by the Psychiatric Genomics Consortium as risk loci, and compared them with gene sets grouped by antipsychotic targets, efficacy, and pharmacokinetic profiles. Interestingly, they observed enrichment of risk loci for antipsychotic targets, revealing genetic overlap between the etiology of schizophrenia and the mechanisms of action of antipsychotics, which is in line with a previous study [91]. Utilizing clozapine as a proxy for identifying cases of treatment refractory schizophrenia, they observed enrichment of rare disruptive variants in gene sets for antipsychotic targets and efficacy in the clozapine group versus the nonclozapine group. Interestingly, similar results were reported by Martin and Mowry [92], who observed increased burden of rare duplications in treatmentresistant schizophrenia. These studies also provide insights into drug development. Demonstrating a genetic overlap between the mechanisms of action of antipsychotic medications and the pathogenesis of schizophrenia supports the idea that understanding clozapine's mechanism of action could improve the treatment of schizophrenia.

Importantly, significant genetic results have already begun to emerge from GWAS related to clozapine treatment, and specific alleles have been identified that could lead to new targets. A study in a UK clozapine clinic (CLOZUK) [93] revealed an overlap of about $47 \%$ in the SNPs previously reported by the Psychiatric Genomics Consortium. In addition, they identified 3 new loci that met genome-wide significance: inter-alpha-trypsin inhibitor heavy chain 3/4 (ITIH3/4); calcium voltage-gated channel subunit alpha1 C (CACNA1C); and serologically defined colon cancer antigen 8 (SDCCAG8). Moreover, a recent study found an association between a previously reported genetic variant in ITIH3/4 and improvement of negative symptoms in patients treated with clozapine [94]. Another study revealed an association between clozapine efficacy and a genetic variant in $D 2 D R$, a risk variant for schizophrenia with genome-wide significance [95]. Studies such as these can help provide targets and potential pathways amenable to intervention both at and beyond neuroreceptors.

\section{Side Effects}

To better understand the mechanism of clozapine's efficacy, it is critical to understand the biology of its side effects for several reasons. First, there may be a biological relationship between clozapine's efficacy and side effects. Evidence exists for a positive correlation between antipsychotic efficacy and metabolic side effects [96, 97]. This relationship is complex, but may be mediated by molecules such as insulin-like growth factor [98], Akt [99, 100], and glycogen synthase kinase, which have all been linked to schizophrenia and glucose metabolism [101-103]. Second, dissecting the pathways mediating therapeutic response to clozapine from those mediating its side effects could lead to improved medications, or possibly a combination of medications, that could produce the same response without the side effects. Third, understanding which patients are likely to develop side effects could optimize the clinical use of clozapine, such as developing treatment or prophylaxis protocols for specific individuals depending on their likelihood of developing certain side effects.

To date, the only clozapine-induced side effects studied in an unbiased manner are neutropenia and weight gain. Results from 2 different GWAS investigations demonstrated the association of human leukocyte antigen (HLA) genetic variants with clozapine-induced agranulocytosis or neutropenia [104, 105], with some of the most promising SNPs occurring in the $H L A-D Q B 1$ and $H L A-B$ loci. Additionally, a novel SNP 
intronic to solute carrier organic anion transporter family member 1B3 (SLCO1B3) and solute carrier organic anion transporter family member $1 \mathrm{~B} 7$ (SLCO1B7), both members of a family of organic anion hepatic transporters, was identified through the GWAS. Furthermore, an exome array analysis found that ubiquitin associated protein 2 and StAR-related lipid transfer domain containing 9 are associated with clozapine-induced neutropenia.

For clozapine-induced weight gain, melanocortin 4 receptor has emerged as a promising gene. It was originally identified from a GWAS of obesity [106] and substantiated in a large GWAS of antipsychotic-induced weight gain [107]. Later, Chowdhury et al. [108] demonstrated the role of melanocortin 4 receptor specifically in clozapine-induced weight gain.

Similar to identifying novel targets for response, identifying specific targets and pathways related to side effects can facilitate the development of novel antipsychotics. So far, while limited in scope, the unbiased studies described above provide insights into the genetics related to clozapine's side effects and could be critical in developing novel medications as we better understand the genes and pathways related to clozapine's side effects.

\section{Gene Expression Profiling}

In addition to pharmacogenomics, gene expression profiling can help to determine the mechanisms of clozapine's superior efficacy beyond neuroreceptor binding. Gene expression profiling can identify specific genes and pathways related to clozapine's mechanism of action, providing novel drug targets. Several studies have examined gene expression changes in postmortem brains of patients on antipsychotic therapy versus healthy controls [109-116]. However, no study of gene expression in the human brain specifically compared patients treated with clozapine with patients treated with other antipsychotics, or with healthy controls.

Therefore, Lee et al. [117] recently performed the first study to analyze gene expression changes specifically in response to clozapine in the human brain. This work extracted primary data from 4 microarray studies of postmortem brains, and analyzed the expression data from patients on clozapine versus patients on other atypical antipsychotics. Each study highlighted a number of genes modulated by clozapine, many of which could be of interest, but 3 results were identified in all 4 of the studies analyzed: glutamate-cysteine ligase modifier subunit (GCLM) and zinc finger protein 652 (ZNF652) were found to be upregulated, and glycophorin $\mathrm{C}$ (GYPC) was found to be downregulated. Four pathways were also highlighted in all of the studies: clathrin-mediated endocytosis, stress-activated protein kinase/c-Jun-terminal kinase signaling, 3-phosphoinositide biosynthesis, and paxillin signaling. Interestingly many of these genes and pathways have been implicated in schizophrenia, further validating this approach [118-123].

Studies as described above provide targets and pathways related to clozapine's impact on gene expression, which are potentially amenable to therapeutic intervention. Developing novel medications that change the regulation of genes altered in schizophrenia, or are affected by clozapine, could yield superior therapies with targets beyond neuroreceptor systems.

\section{Summary of Frontline Approaches}

Both pharmacogenetics and pharmacogenomics have strengths in understanding clozapine's mechanism of action, providing strategies to identify therapeutic targets and develop new medications. Pharmacogenetics has provided insights into the genetics of response and side effects, mainly with candidate genes related to neuroreceptors.

Pharmacogenomics and gene expression profiling provide useful tools to identify novel targets for therapeutic intervention in an unbiased manner. The studies described above highlight several key points. First, there is genetic overlap between the mechanisms of action of antipsychotics and the pathogenesis of schizophrenia. This supports the idea that understanding clozapine's mechanism of action could not only lead to valid therapeutic targets, but also elucidate the complex pathophysiology of schizophrenia. Second, higher rates of PRS are associated with refractory schizophrenia and clozapine use, indicating that medications with multiple targets or a combination of medications may be necessary to treat severe cases of schizophrenia. It also suggests that higher PRS could serve as a useful marker for prescribing clozapine as a first-line antipsychotic. Third, pathways other than neurotransmitter systems are important, as most of the genes or pathways described above are not directly linked to the neurotransmitter receptors thought to underlie clozapine's superior efficacy. Finally, novel genes and pathways have begun to emerge from these unbiased studies. All of these studies provide evidence that further investigation into the functional implication of these genetic variants, and identifying specific genes and pathways from gene expression profiling, would help elucidate clozapine's mechanism of action, leading to novel therapeutic targets and potentially new and more efficacious medications.

\section{Future Studies and Novel Approaches}

Unfortunately, decades of altering neuroreceptor profiles have not led to medications with greater efficacy than clozapine. The studies described in this review begin to offer clues to clozapine's mechanism of action. Further studies using unbiased approaches to identify genes and pathways, or addressing promising candidate genes beyond neuroreceptors, are needed to obtain a fuller understanding of clozapine's mechanism of 
action and to identify drug targets. Utilizing biospecimens, future studies could introduce patient stratification based on clinical symptomatology, response to clozapine, or side effects. Stratifying patients in these ways would provide a fuller picture of clozapine's mechanism of action and delineate, for example, response from side effects. Pre- and post-clozapine experimental design would eliminate interindividual differences, and longitudinally capture genes and pathways contributing to response, side effects, or a common mechanism mediating both. Once patients are stratified, pharmacogenetics, pharmacogenomics, or gene expression profiling can be performed. Information identified from molecular and preclinical studies, which are beyond the scope of this review, could also help inform our understanding of clozapine and aid the development of potential candidate targets. The most promising targets from all of these approaches can be further studied in model systems and then utilized for drug development.

In the 30 years since the first landmark study on clozapine in the US, over a dozen antipsychotics have been marketed, without succeeding in improving on clozapine's efficacy. Therefore, approaches that can identify specific genes and pathways, as novel drug targets beyond neuroreceptor binding, hold promise to elucidate the mechanisms of clozapine's action and side effects, as well as the complex pathophysiology of schizophrenia. Insights gained from these approaches are critical for the development of novel therapeutics that could advance the current state of antipsychotic therapy.

Acknowledgments This work was supported by the National Institute of Mental Health MH-094268 Silvio O. Conte center, MH-092443, MH105660 (AS); National Institute on Drug Abuse DA-040127 (AS); foundation grants from Stanley, S-R, RUSK, NARSAD, Maryland Stem Cell Research Fund (AS). We would also like to thank Yukiko Lema for help with this manuscript.

Required Author Forms Disclosure forms provided by the authors are available with the online version of this article.

\section{References}

1. Perala J, Suvisaari J, Saarni SI, et al. Lifetime prevalence of psychotic and bipolar I disorders in a general population. Arch Gen Psychiatry 2007;64(1):19-28.

2. Saha S, Chant D, Welham J, McGrath J. A systematic review of the prevalence of schizophrenia. PLOS Med 2005;2(5):e141.

3. Owen MJ, Sawa A, Mortensen PB. Schizophrenia. Lancet 2016;388(10039):86-97.

4. Schulz SC, Murray A. Assessing cognitive impairment in patients with schizophrenia. J Clin Psychiatry. 2016;77(Suppl. 2):3-7.

5. Palmer BA, Pankratz VS, Bostwick JM. The lifetime risk of suicide in schizophrenia: a reexamination. Arch Gen Psychiatry 2005;62(3):247-253.

6. Hor K, Taylor M. Suicide and schizophrenia: a systematic review of rates and risk factors. J Psychopharmacol 2010;24(4 Suppl.): 81-90.
7. Brown S, Kim M, Mitchell C, Inskip H. Twenty-five year mortality of a community cohort with schizophrenia. Br J Psychiatry 2010;196(2):116-121.

8. Crump C, Winkleby MA, Sundquist K, Sundquist J. Comorbidities and mortality in persons with schizophrenia: a Swedish national cohort study. Am J Psychiatry 2013;170(3): 324-333.

9. Cloutier M, Aigbogun MS, Guerin A, et al. The economic burden of schizophrenia in the United States in 2013. J Clin Psychiatry 2016;77(6):764-771.

10. Conley RR, Kelly DL. Management of treatment resistance in schizophrenia. Biol Psychiatry 2001;50(11):898-911.

11. Miyamoto S, Jarskog LF, Fleischhacker WW. New therapeutic approaches for treatment-resistant schizophrenia: a look to the future. J Psychiatr Res 2014;58:1-6.

12. Meltzer HY. Treatment of the neuroleptic-nonresponsive schizophrenic patient. Schizophr Bull 1992;18(3):515-542.

13. Shen WW. A history of antipsychotic drug development. Compr Psychiatry 1999;40(6):407-414.

14. Preskorn SH. CNS drug development. Part I: the early period of CNS drugs. J Psychiatr Pract 2010;16(5):334-339.

15. Crilly J. The history of clozapine and its emergence in the US market: a review and analysis. Hist Psychiatry 2007;18(1):39-60.

16. Tamminga CA. Treatment mechanisms: traditional and new antipsychotic drugs. Dialogues Clin Neurosci 2000;2(3):281-286.

17. Baldessarini RJ, Frankenburg FR. Clozapine. A novel antipsychotic agent. N Engl J Med 1991;324(11):746-754.

18. Lindstrom LH. The effect of long-term treatment with clozapine in schizophrenia: a retrospective study in 96 patients treated with clozapine for up to 13 years. Acta Psychiatr Scand 1988;77(5): 524-529.

19. Kane J, Honigfeld G, Singer J, Meltzer H. Clozapine for the treatment-resistant schizophrenic. A double-blind comparison with chlorpromazine. Arch Gen Psychiatry 1988;45(9):789-796.

20. McEvoy JP, Lieberman JA, Stroup TS, et al. Effectiveness of clozapine versus olanzapine, quetiapine, and risperidone in patients with chronic schizophrenia who did not respond to prior atypical antipsychotic treatment. Am J Psychiatry 2006;163(4): 600-610.

21. Lewis SW, Barnes TR, Davies L, et al. Randomized controlled trial of effect of prescription of clozapine versus other secondgeneration antipsychotic drugs in resistant schizophrenia. Schizophr Bull 2006;32(4):715-723.

22. Siskind D, McCartney L, Goldschlager R, Kisely S. Clozapine v. first- and second-generation antipsychotics in treatment-refractory schizophrenia: systematic review and meta-analysis. Br J Psychiatry 2016;209(5):385-392.

23. Leucht S, Cipriani A, Spineli L, et al. Comparative efficacy and tolerability of 15 antipsychotic drugs in schizophrenia: a multipletreatments meta-analysis. Lancet 2013;382(9896):951-962.

24. Meltzer HY, Alphs L, Green AI, et al. Clozapine treatment for suicidality in schizophrenia: International Suicide Prevention Trial (InterSePT). Arch Gen Psychiatry 2003;60(1):82-91.

25. Glazer WM, Dickson RA. Clozapine reduces violence and persistent aggression in schizophrenia. J Clin Psychiatry. 1998;59(Suppl. 3):8-14.

26. Atkin K, Kendall F, Gould D, Freeman H, Liberman J, O'Sullivan D. Neutropenia and agranulocytosis in patients receiving clozapine in the UK and Ireland. Br J Psychiatry 1996;169(4):483-488.

27. Honigfeld G, Arellano F, Sethi J, Bianchini A, Schein J. Reducing clozapine-related morbidity and mortality: 5 years of experience with the Clozaril National Registry. J Clin Psychiatry 1998;59(Suppl. 3):3-7.

28. Merrill DB, Ahmari SE, Bradford JM, Lieberman JA. Myocarditis during clozapine treatment. Am J Psychiatry 2006;163(2):204208. 
29. Paciullo CA. Evaluating the association between clozapine and venous thromboembolism. Am J Health Syst Pharm 2008; 65(19): 1825-1829.

30. Devinsky O, Honigfeld G, Patin J. Clozapine-related seizures. Neurology 1991;41(3):369-371.

31. Varma S, Bishara D, Besag FM, Taylor D. Clozapine-related EEG changes and seizures: dose and plasma-level relationships. Ther Adv Psychopharmacol 2011;1(2):47-66.

32. Palmer SE, McLean RM, Ellis PM, Harrison-Woolrych M. Lifethreatening clozapine-induced gastrointestinal hypomotility: an analysis of 102 cases. J Clin Psychiatry 2008;69(5):759-768.

33. Henderson DC, Nguyen DD, Copeland PM, et al. Clozapine, diabetes mellitus, hyperlipidemia, and cardiovascular risks and mortality: results of a 10-year naturalistic study. J Clin Psychiatry 2005;66(9):1116-1121.

34. Meltzer HY. Clozapine: balancing safety with superior antipsychotic efficacy. Clin Schizophr Relat Psychoses 2012;6(3):134144.

35. Howes OD, Vergunst F, Gee S, McGuire P, Kapur S, Taylor D. Adherence to treatment guidelines in clinical practice: study of antipsychotic treatment prior to clozapine initiation. Br J Psychiatry 2012;201(6):481-485.

36. Edwards J, Maude D, McGorry PD, Harrigan SM, Cocks JT. Prolonged recovery in first-episode psychosis. Br J Psychiatry Suppl 1998;172(33):107-116.

37. Su TP, Malhotra AK, Hadd K, Breier A, Pickar D. D2 dopamine receptor occupancy: a crossover comparison of risperidone with clozapine therapy in schizophrenic patients. Arch Gen Psychiatry 1997;54(10):972-973.

38. Miyamoto S, Duncan GE, Marx CE, Lieberman JA. Treatments for schizophrenia: a critical review of pharmacology and mechanisms of action of antipsychotic drugs. Mol Psychiatry 2005;10(1):79-104.

39. Kusumi I, Boku S, Takahashi Y. Psychopharmacology of atypical antipsychotic drugs: From the receptor binding profile to neuroprotection and neurogenesis. Psychiatry Clin Neurosci 2015;69(5):243-258.

40. Corena-McLeod M. Comparative pharmacology of risperidone and paliperidone. Drugs R D 2015;15(2):163-174.

41. Richelson E. New antipsychotic drugs: how do their receptorbinding profiles compare? J Clin Psychiatry 2010;71(9):12431244.

42. Shahid M, Walker GB, Zorn SH, Wong EH. Asenapine: a novel psychopharmacologic agent with a unique human receptor signature. J Psychopharmacol 2009;23(1):65-73.

43. Ishibashi T, Horisawa T, Tokuda K, et al. Pharmacological profile of lurasidone, a novel antipsychotic agent with potent 5hydroxytryptamine 7 (5-HT7) and 5-HT1A receptor activity. J Pharmacol Exp Ther 2010;334(1):171-181.

44. Albers LJ, Musenga A, Raggi MA. Iloperidone: a new benzisoxazole atypical antipsychotic drug. Is it novel enough to impact the crowded atypical antipsychotic market? Expert Opin Investig Drugs 2008;17(1):61-75.

45. Howes OD, Egerton A, Allan V, McGuire P, Stokes P, Kapur S. Mechanisms underlying psychosis and antipsychotic treatment response in schizophrenia: insights from PET and SPECT imaging. Curr Pharm Des 2009;15(22):2550-2559.

46. Kapur S, Zipursky RB, Remington G. Clinical and theoretical implications of 5-HT2 and D2 receptor occupancy of clozapine, risperidone, and olanzapine in schizophrenia. Am J Psychiatry 1999;156(2):286-293.

47. Pani L, Pira L, Marchese G. Antipsychotic efficacy: relationship to optimal D2-receptor occupancy. Eur Psychiatry 2007;22(5):267275.

48. Meltzer HY. The mechanism of action of novel antipsychotic drugs. Schizophr Bull 1991;17(2):263-287.
49. Kapur S, Seeman P. Does fast dissociation from the dopamine d(2) receptor explain the action of atypical antipsychotics?: A new hypothesis. Am J Psychiatry 2001;158(3):360-369.

50. Seeman P. Atypical antipsychotics: mechanism of action. Can J Psychiatry 2002;47(1):27-38.

51. Meltzer HY, Matsubara S, Lee JC. The ratios of serotonin2 and dopamine2 affinities differentiate atypical and typical antipsychotic drugs. Psychopharmacol Bull 1989;25(3):390-392.

52. Ebdrup BH, Rasmussen H, Arnt J, Glenthoj B. Serotonin 2A receptor antagonists for treatment of schizophrenia. Expert Opin Investig Drugs 2011;20(9):1211-1223.

53. Kulkarni SK, Ninan I. Dopamine D4 receptors and development of newer antipsychotic drugs. Fundam Clin Pharmacol 2000;14(6):529-539.

54. Tarazi FI, Zhang K, Baldessarini RJ. Dopamine D4 receptors: beyond schizophrenia. J Recept Signal Transduct Res 2004;24(3):131-147.

55. Svensson TH. Alpha-adrenoceptor modulation hypothesis of antipsychotic atypicality. Prog Neuropsychopharmacol Biol Psychiatry 2003;27(7):1145-1158.

56. Hommer DW, Zahn TP, Pickar D, van Kammen DP. Prazosin, a specific alpha 1-noradrenergic receptor antagonist, has no effect on symptoms but increases autonomic arousal in schizophrenic patients. Psychiatry Res 1984;11(3):193-204.

57. Friedman JI, Adler DN, Temporini HD, et al. Guanfacine treatment of cognitive impairment in schizophrenia. Neuropsychopharmacology 2001;25(3):402-409.

58. Rajji TK, Mulsant BH, Davies S, et al. Prediction of working memory performance in schizophrenia by plasma ratio of clozapine to N-desmethylclozapine. Am J Psychiatry 2015;172(6):579585.

59. Foster DJ, Choi DL, Conn PJ, Rook JM. Activation of M1 and M4 muscarinic receptors as potential treatments for Alzheimer's disease and schizophrenia. Neuropsychiatr Dis Treat 2014;10:183191.

60. Shekhar A, Potter WZ, Lightfoot J, et al. Selective muscarinic receptor agonist xanomeline as a novel treatment approach for schizophrenia. Am J Psychiatry 2008;165(8):1033-1039.

61. Humbert-Claude M, Davenas E, Gbahou F, Vincent L, Arrang JM. Involvement of histamine receptors in the atypical antipsychotic profile of clozapine: a reassessment in vitro and in vivo. Psychopharmacology (Berl) 2012;220(1):225-241.

62. Meskanen K, Ekelund H, Laitinen J, et al. A randomized clinical trial of histamine 2 receptor antagonism in treatment-resistant schizophrenia. J Clin Psychopharmacol 2013;33(4):472-478.

63. Kroeze WK, Hufeisen SJ, Popadak BA, et al. H1-histamine receptor affinity predicts short-term weight gain for typical and atypical antipsychotic drugs. Neuropsychopharmacology 2003;28(3):519526.

64. Bozymski KM, Lowe DK, Pasternak KM, Gatesman TL, Crouse EL. Pimavanserin: a novel antipsychotic for parkinson's disease psychosis. Ann Pharmacother 2017;51(6):479-487.

65. Meltzer HY, Mills R, Revell S, et al. Pimavanserin, a serotonin(2A) receptor inverse agonist, for the treatment of parkinson's disease psychosis. Neuropsychopharmacology 2010;35(4):881-892.

66. Meltzer HY, Elkis H, Vanover K, et al. Pimavanserin, a selective serotonin (5-HT)2A-inverse agonist, enhances the efficacy and safety of risperidone, $2 \mathrm{mg}$ /day, but does not enhance efficacy of haloperidol, $2 \mathrm{mg}$ /day: comparison with reference dose risperidone, 6mg/day. Schizophr Res 2012;141(2-3):144-152.

67. Gressier F, Porcelli S, Calati R, Serretti A. Pharmacogenetics of clozapine response and induced weight gain: a comprehensive review and meta-analysis. Eur Neuropsychopharmacol 2016;26(2):163-185. 
68. Lally J, Gaughran F, Timms P, Curran SR. Treatment-resistant schizophrenia: current insights on the pharmacogenomics of antipsychotics. Pharmgenomics Pers Med 2016;9:117-129.

69. Krivoy A, Gaughran F, Weizman A, Breen G, MacCabe JH. Gene polymorphisms potentially related to the pharmacokinetics of clozapine: a systematic review. Int Clin Psychopharmacol 2016;31(4):179-184.

70. Sriretnakumar V, Huang E, Muller DJ. Pharmacogenetics of clozapine treatment response and side-effects in schizophrenia: an update. Expert Opin Drug Metab Toxicol 2015;11(11):1709-1731.

71. Lin CH, Tsai SJ, Yu YW, et al. No evidence for association of serotonin-2A receptor variant (102T/C) with schizophrenia or clozapine response in a Chinese population. Neuroreport 1999;10(1): 57-60.

72. Lee ST, Ryu S, Kim SR, et al. Association study of 27 annotated genes for clozapine pharmacogenetics: validation of preexisting studies and identification of a new candidate gene, ABCB1, for treatment response. J Clin Psychopharmacol 2012;32(4):441-448.

73. Akamine Y, Sugawara-Kikuchi Y, Uno T, Shimizu T, Miura M. Quantification of the steady-state plasma concentrations of clozapine and N-desmethylclozapine in Japanese patients with schizophrenia using a novel HPLC method and the effects of CYPs and ABC transporters polymorphisms. Ann Clin Biochem 2017: 4563216686377.

74. $\mathrm{Xu} \mathrm{Q}, \mathrm{Wu} \mathrm{X}, \mathrm{Li} \mathrm{M}$, et al. Association studies of genomic variants with treatment response to risperidone, clozapine, quetiapine and chlorpromazine in the Chinese Han population. Pharmacogenomics J 2016;16(4):357-365.

75. Arranz MJ, Munro J, Sham P, et al. Meta-analysis of studies on genetic variation in 5-HT2A receptors and clozapine response. Schizophr Res 1998;32(2):93-99.

76. Lett TA, Wallace TJ, Chowdhury NI, Tiwari AK, Kennedy JL, Muller DJ. Pharmacogenetics of antipsychotic-induced weight gain: review and clinical implications. Mol Psychiatry 2012;17(3):242-266.

77. Zhang JP, Malhotra AK. Pharmacogenetics of antipsychotics: recent progress and methodological issues. Expert Opin Drug Metab Toxicol 2013;9(2):183-191.

78. Nothen MM, Rietschel M, Erdmann J, et al. Genetic variation of the 5-HT2A receptor and response to clozapine. Lancet 1995;346(8979):908-909.

79. Malhotra AK, Goldman D, Ozaki N, Breier A, Buchanan R, Pickar D. Lack of association between polymorphisms in the 5HT2A receptor gene and the antipsychotic response to clozapine. Am J Psychiatry 1996;153(8):1092-1094.

80. Masellis M, Basile V, Meltzer HY, et al. Serotonin subtype 2 receptor genes and clinical response to clozapine in schizophrenia patients. Neuropsychopharmacology 1998;19(2):123-132.

81. Schumacher J, Schulze TG, Wienker TF, Rietschel M, Nothen MM. Pharmacogenetics of the clozapine response. Lancet 2000;356(9228):506-507.

82. Brown AS. The environment and susceptibility to schizophrenia. Prog Neurobiol 2011;93(1):23-58.

83. McGrath JJ, Mortensen PB, Visscher PM, Wray NR. Where GWAS and epidemiology meet: opportunities for the simultaneous study of genetic and environmental risk factors in schizophrenia. Schizophr Bull 2013;39(5):955-959.

84. Kannan G, Sawa A, Pletnikov MV. Mouse models of geneenvironment interactions in schizophrenia. Neurobiol Dis 2013;57:5-11.

85. International Schizophrenia Consortium, Purcell SM, Wray NR, et al. Common polygenic variation contributes to risk of schizophrenia and bipolar disorder. Nature 2009;460(7256):748-752

86. Wray NR, Goddard ME, Visscher PM. Prediction of individual genetic risk to disease from genome-wide association studies. Genome Res 2007;17(10):1520-1528.
87. Euesden J, Lewis CM, O'Reilly PF. PRSice: Polygenic Risk Score software. Bioinformatics 2015;31(9):1466-1468.

88. Levine ME, Crimmins EM, Prescott CA, Phillips D, Arpawong TE, Lee J. A polygenic risk score associated with measures of depressive symptoms among older adults. Biodemography Soc Biol 2014;60(2):199-211.

89. Frank J, Lang M, Witt SH, et al. Identification of increased genetic risk scores for schizophrenia in treatment-resistant patients. Mol Psychiatry 2015;20(2):150-151.

90. Ruderfer DM, Charney AW, Readhead B, et al. Polygenic overlap between schizophrenia risk and antipsychotic response: a genomic medicine approach. Lancet Psychiatry 2016;3(4):350-357.

91. Ikeda M, Yoshimura R, Hashimoto R, et al. Genetic overlap between antipsychotic response and susceptibility to schizophrenia. J Clin Psychopharmacol 2015;35(1):85-88.

92. Martin AK, Mowry B. Increased rare duplication burden genomewide in patients with treatment-resistant schizophrenia. Psychol Med 2016;46(3):469-476.

93. Hamshere ML, Walters JT, Smith R, et al. Genome-wide significant associations in schizophrenia to ITIH3/4, CACNA1C and SDCCAG8, and extensive replication of associations reported by the Schizophrenia PGC. Mol Psychiatry 2013;18(6):708-712.

94. Brandl EJ, Lett TA, Chowdhury NI, et al. The role of the ITIH3 rs2535629 variant in antipsychotic response. Schizophr Res 2016;176(2-3):131-135.

95. Huang E, Maciukiewicz M, Zai CC, et al. Preliminary evidence for association of genome-wide significant DRD2 schizophrenia risk variant with clozapine response. Pharmacogenomics 2016;17(2):103-109.

96. Girgis RR, Javitch JA, Lieberman JA. Antipsychotic drug mechanisms: links between therapeutic effects, metabolic side effects and the insulin signaling pathway. Mol Psychiatry 2008;13(10): 918-929.

97. Newcomer JW. Metabolic considerations in the use of antipsychotic medications: a review of recent evidence. J Clin Psychiatry 2007;68(Suppl. 1):20-27.

98. Gunnell D, Holly JM. Do insulin-like growth factors underlie associations of birth complications, fetal and pre-adult growth with schizophrenia? Schizophr Res 2004;67(2-3):309-311.

99. Zhao Z, Ksiezak-Reding H, Riggio S, Haroutunian V, Pasinetti GM. Insulin receptor deficits in schizophrenia and in cellular and animal models of insulin receptor dysfunction. Schizophr Res 2006;84(1):1-14.

100. Thiselton DL, Vladimirov VI, Kuo PH, et al. AKT1 is associated with schizophrenia across multiple symptom dimensions in the Irish study of high density schizophrenia families. Biol Psychiatry 2008;63(5):449-457.

101. Kozlovsky N, Belmaker RH, Agam G. Low GSK-3beta immunoreactivity in postmortem frontal cortex of schizophrenic patients. Am J Psychiatry 2000;157(5):831-833.

102. Kozlovsky N, Belmaker RH, Agam G. Low GSK-3 activity in frontal cortex of schizophrenic patients. Schizophr Res 2001;52(1-2):101-105.

103. Beasley C, Cotter D, Khan N, et al. Glycogen synthase kinase3 beta immunoreactivity is reduced in the prefrontal cortex in schizophrenia. Neurosci Lett 2001;302(2-3):117-120.

104. Goldstein JI, Jarskog LF, Hilliard C, et al. Clozapine-induced agranulocytosis is associated with rare HLA-DQB1 and HLA-B alleles. Nat Commun 2014;5:4757.

105. Legge SE, Hamshere ML, Ripke S, et al. Genome-wide common and rare variant analysis provides novel insights into clozapineassociated neutropenia. Mol Psychiatry 2016 Aug 9 [Epub ahead of print].

106. Thorleifsson G, Walters GB, Gudbjartsson DF, et al. Genomewide association yields new sequence variants at seven loci that associate with measures of obesity. Nat Genet 2009;41(1):18-24. 
107. Malhotra AK, Correll CU, Chowdhury NI, et al. Association between common variants near the melanocortin 4 receptor gene and severe antipsychotic drug-induced weight gain. Arch Gen Psychiatry 2012;69(9):904-912.

108. Chowdhury NI, Tiwari AK, Souza RP, et al. Genetic association study between antipsychotic-induced weight gain and the melanocortin-4 receptor gene. Pharmacogenomics J 2013;13(3): 272-279.

109. Aston C, Jiang L, Sokolov BP. Microarray analysis of postmortem temporal cortex from patients with schizophrenia. J Neurosci Res 2004;77(6):858-866.

110. Chen H, Wang N, Zhao X, Ross CA, O'Shea KS, McInnis MG. Gene expression alterations in bipolar disorder postmortem brains. Bipolar Disord 2013;15(2):177-187.

111. Iwamoto K, Bundo M, Kato T. Altered expression of mitochondria-related genes in postmortem brains of patients with bipolar disorder or schizophrenia, as revealed by large-scale DNA microarray analysis. Hum Mol Genet 2005;14(2):241-253.

112. Mudge J, Miller NA, Khrebtukova I, et al. Genomic convergence analysis of schizophrenia: mRNA sequencing reveals altered synaptic vesicular transport in post-mortem cerebellum. PLOS ONE 2008;3(11):e3625.

113. Pietersen CY, Mauney SA, Kim SS, et al. Molecular profiles of pyramidal neurons in the superior temporal cortex in schizophrenia. J Neurogenet 2014;28(1-2):53-69.

114. Pietersen CY, Mauney SA, Kim SS, et al. Molecular profiles of parvalbumin-immunoreactive neurons in the superior temporal cortex in schizophrenia. J Neurogenet 2014;28(1-2):70-85.

115. Schmitt A, Leonardi-Essmann F, Durrenberger PF, et al. Regulation of immune-modulatory genes in left superior temporal cortex of schizophrenia patients: a genome-wide microarray study. World J Biol Psychiatry 2011;12(3):201-215.

116. Wu JQ, Wang X, Beveridge NJ, et al. Transcriptome sequencing revealed significant alteration of cortical promoter usage and splicing in schizophrenia. PLOS ONE 2012;7(4):e36351.

117. Lee BJ, Marchionni L, Andrews CE, et al. Analysis of differential gene expression mediated by clozapine in human postmortem brains. Schizophr Res 2016 Dec 17 [Epub ahead of print].

118. Steullet P, Cabungcal JH, Monin A, et al. Redox dysregulation, neuroinflammation, and NMDA receptor hypofunction: A "central hub" in schizophrenia pathophysiology? Schizophr Res 2016;176(1):41-51.

119. Tosic M, Ott J, Barral S, et al. Schizophrenia and oxidative stress: glutamate cysteine ligase modifier as a susceptibility gene. Am J Hum Genet 2006;79(3):586-592.

120. Law AJ, Wang Y, Sei Y, et al. Neuregulin 1-ErbB4-PI3K signaling in schizophrenia and phosphoinositide 3-kinase-p110delta inhibition as a potential therapeutic strategy. Proc Natl Acad Sci U S A 2012;109(30):12165-12170.

121. Morris BJ, Pratt JA. Novel treatment strategies for schizophrenia from improved understanding of genetic risk. Clin Genet 2014;86(5):401-411.

122. Rosse C, Formstecher E, Boeckeler K, et al. An aPKC-exocyst complex controls paxillin phosphorylation and migration through localised JNK1 activation. PLOS Biol 2009;7(11):e1000235.

123. Schubert KO, Focking M, Prehn JH, Cotter DR. Hypothesis review: are clathrin-mediated endocytosis and clathrin-dependent membrane and protein trafficking core pathophysiological processes in schizophrenia and bipolar disorder? Mol Psychiatry 2012;17(7):669-681. 